\title{
Serviced apartment complexes in Australia: a critical analysis of their potential and challenges for sustainable tourism
}

\author{
J. Warnken ${ }^{1}$ \& C. Guilding ${ }^{2}$ \\ ${ }^{1}$ Service Industry Research Centre and School of Environmental and \\ Applied Sciences, Griffith University, Australia \\ ${ }^{2}$ Service Industry Research Centre and Department of Tourism, Leisure, \\ Hotel and Sport Management, Griffith University, Australia
}

\begin{abstract}
Over the past 15 years, the Australian tourism accommodation sector has seen a significant shift from motels and caravan parks to units in multi-owner tourism accommodation premises, i.e. serviced apartments and holiday flats. It is estimated that by the end of 2006, the number of guest nights in serviced apartment complexes will have exceeded those for motels and, in some destinations, even those for hotels. The key difference between traditional hotels, motels, and caravan parks on the one hand, and serviced apartments on the other, is their ownership structure: practically all apartment complexes in Australia are subdivided into as many titles as there are units, and are commonly owned by as many parties. The multiple-owner tourist accommodation (MOTA) form of enterprise has the capacity to attract large amounts of capital that would not be available to other tourist accommodation types, but its multi-ownership structure also poses some major challenges for the long-term sustainability of a destination reliant on MOTA-type complexes.

This paper examines the potentials and possible pitfalls of MOTA-style development in Australia and its premier domestic destination, Queensland's Gold Coast. It also identifies the factors accounting for the increased incidence of MOTA.
\end{abstract}

Keywords: accommodation, multi-title, second home, management, destination, rejuvenation. 


\section{Introduction}

Until the early 1990s, the Australian tourism accommodation sector was dominated by three main forms of accommodation: caravan parks and camp grounds, hotels and motels, and holiday homes [1]. While the motel and caravan park sectors stagnated, growth in the holiday home sector was considerable. This growth, however, has received very little attention [2, 3] despite a recent reinvigoration in the wake of the "Sea Change" phenomenon [4] which has seen an amenity driven migration to seaside locations.

The ongoing demand for holiday home style accommodation and the increasing scarcity of inexpensive land in popular beach and ski resort destinations has accelerated the evolution of traditional holiday homes into a new tourist accommodation paradigm: multi-owner tourist accommodation (MOTA) complexes. In essence, MOTA complexes provide the opportunity to continue developing holiday home-style accommodation units that share one or several walls and a common property to achieve higher densities in increasingly urbanised destinations [5,6]. The multi owner structure opens up opportunities for many small investors and real estate agents to participate in the frequently financially rewarding game of tourism and amenity-based property investment speculation $[7,8]$.

The diversity of interests of investors (supply side) and travellers (demand side) has resulted in a diverse range of MOTA complexes. Overall, however, they share three key common elements:

1. They encompass some common property and more than one separate property title linked to the common property or land parcel.

2. They are typically owned by several independent owners.

3. They are subject to local governance provisions which are administered by the owners' overarching body (the body corporate or owners association), according to a constitution applying to the complex. Amendments to this constitution can usually only be achieved following the unanimous consent of all owners $[9,10]$ in the scheme.

It is this multi-ownership structure that lies at the nub of MOTA's additional challenge to sustainable tourism development, and that has prompted this review of some of the inherent threats to sustainability associated with reliance on MOTA complexes when developing a destination's bed capacity.

\section{Growth of MOTA complexes in Australia}

Documenting the growth of this sector in Australia was facilitated in 1998 by a change in the way the Australian Bureau of Statistics' accommodation survey categorised tourism accommodation. From this date, the category 'serviced apartments' was introduced ("...Self-contained units at the same location, [...] which are available on a unit/apartment basis to the general public for a minimum of one night. The units should have full cooking facilities (i.e. hot plates and oven/microwave), refrigerator and bath/shower and toilet facilities." (Australian Bureau of Statistics. Tourist Accommodation Survey, Canberra, 
2005). In Australia, serviced apartments are almost exclusively subject to multiple ownership structures. Visits by the authors to various destinations in Australia have highlighted, however, that a considerable number of MOTA complexes are classified as 'holiday homes and flats', as provision of bed linen and towels cannot be met by the on-site managers. Between 1998 and 2005, the number of letting entities, rooms, guest nights and takings increased for 'serviced apartments' by $77 \%, 104 \%, 129 \%$ and $169 \%$, respectively. Over the same period, the equivalent statistics for 'motels' were $6 \%, 4 \%, 7 \%$ and $32 \%$; and for 'hotels' were $11 \%, 16 \%, 33 \%$ and $49 \%$ (see Figure 1). Extrapolation of these data trends indicates that takings from 'serviced apartments' will exceed those from motels by mid 2007. It is expected that in the next reporting period of 'holiday homes and flats' in 2006, the number of rooms provided in 'serviced apartments' and 'holiday homes and flats' will have surpassed the number of rooms in motels.

Information from hotel accommodation providers on the Gold Coast and a review of recent investment in the tourist resort sector [11] further indicate that a number of properties listed as hotels are either partly or fully strata-titled ("Strata title" is the term used in Australia for complexes that are subject to multiple ownership titles). Also, some caravan park sites and 'units' in backpacker-style accommodation complexes can be strata-titled and individually sold. The overall number of MOTA complexes is therefore likely to be much higher than that reflected by the data for 'serviced apartments'. Based on data for 'serviced apartments' alone and a conservative average market price of AUD 125,000 per bedroom in a MOTA unit, the overall investment in this sector over the past seven years would have exceeded AUD 3 billion.

Such a reliance on MOTA style development beckons two questions: what factors are driving this new form of tourism accommodation ownership in Australia, and what challenges are posed by a high reliance on MOTA developments?

\section{Forces accounting for MOTA development}

\subsection{Property developers}

Developers play the pivotally significant role of deciding what types of complexes are to be designed and constructed. Decisions made by a developer at the front end of a complex's life are largely irreversible. Once constructed, the costs of reconfiguring a building in a way to service the needs of a distinctly different end user group will be prohibitively expensive. Developers can also gain the largest returns from a single MOTA development. This motivates a closer inspection of factors motivating developers to build these types of complexes.

Firstly, in MOTA complexes the units can be marketed 'off the plan', i.e. before any construction of the building has commenced. The receipt of funds for units sold off the plan reduces the financial risk borne by either the developer or a lending institution during a complex's construction. The ability to minimise this risk is a key factor attracting developers to MOTA construction. 
Secondly, many MOTA complexes are not restricted to tourism use, i.e. they include long-term residential as well as short-term rental units. Developers are able to finance developments more easily if the development has broad market appeal, rather than restricted to a narrowly defined, tourism-based market. A broader market signifies easier access to the ultimate unit owners' funds.

A third incentive for developers to build MOTA complexes in preference to conventional single title tourism accommodation complexes stems from the fact that the MOTA complex represents a vehicle facilitating small investor access to ownership of property in large tourism accommodation complexes. By breaking up a complex into units of ownership, a developer can draw on a much broader market that includes small investors than if the complex were to be subject to a single ownership title. It is notable that in the late 1980s some Australian developers entrapped several large overseas investors in development projects that never fulfilled their expectations (see [12]).

This broader market for investment capital signifies that a new set of factors come into play with respect to the investors' motivation and psyche. The advent of more small tourism accommodation investors signifies more unsophisticated investors. (The widespread use of guaranteed investment returns for the first three years' of unit ownership which is offered by many developers suggests a particular dimension of unsophistication that may be present amongst small investors. Investors should not believe that the guaranteed rate of return can be sustained beyond the guarantee period. If they do, they will be over estimating the projected returns associated with ownership and unwittingly increasing the valuation placed on the unit). Many small investors can be expected to be attracted to MOTA unit ownership by a range of factors that can include: the image of a leisure-oriented life style (or holiday home), ostentation, the desire to own a future retirement residence, the desire to diversify a pension investment portfolio, and a quest for tax write-offs allowed for by this type of investment in Australia. The first three of these five factors are not present in a corporation's decision to invest in a tourism accommodation complex, which is likely to be more motivated by economic rationale. This signifies that, the need for developers to demonstrate projected financial returns to small investors is not as great as when dealing with a single large investor with its more narrowly focused profit motive.

A fourth factor motivating Australian developers to engage in MOTA developments is that it provides the option of retaining ownership over selected units thereby facilitating the pursuit of a potential real estate speculation motive. Also, in Queensland and NSW, it provides the opportunity to sell management rights for the building, which has been termed "icing on the cake" and can command considerable values [10].

\subsection{Real estate agents}

A second stakeholder group, real estate agents, also appear to profit greatly from MOTA developments. The intended construction of a MOTA complex creates immediate activity for real estate agents engaged to sell units off the plan. When assigned a large volume of similarly designed contiguous units, a real estate 
agent can realise significant economies of scale. Once the initial period of sales to new unit owners elapses, it will be replaced by unit resales for the life of the building, with the majority of sales being brokered by real estate agents. In many smaller MOTA complexes, real estate agents will also benefit by acting as letting agents and building managers. This on-going volume of activity generated for real estate agents by MOTA complexes is considerable when compared to hotel developments. If a large hotel is sold, the sale is rarely mediated by a real estate agency, it is more likely to be brokered by a specialised investment company; also, a real estate agency does not become involved in the sub-letting of hotel rooms. Recognising real estate agents' interest in MOTA developments, and the ability of real estate agents to reap economies of scale when selling off the plan signifies that real estate agents are likely to offer their services to developers using greatly discounted fee structures.

\subsection{Tourists}

Tourists represent a further stakeholder group that stands to benefit from increased MOTA development. MOTA complexes satisfy the desire for self catering short holidays amongst young families and self catering accommodation for increasingly wealthy retirees who wish to escape extreme winter and summer weather conditions. By foregoing the provision of higher service levels (e.g., 24 hours reception facilities), and by increasing the number of users per unit rented, relative to hotels or motels, operators of low key MOTA complexes can offer lower per person prices for similarly sized rented areas. The provision of a fully equipped kitchen and laundry facilities, which is commonly required by financiers and building societies of smaller MOTA buildings, is particularly important to price conscious travellers.

\subsection{Host communities}

Australian host communities may also derive particular benefits from MOTA complexes. Most MOTA on-site managers and operators, and in particular those in medium-sized and larger buildings tend to outsource a large number of tasks (landscaping, pool and linen cleaning, window cleaning, etc.) rather than employ their own staff. This provides business opportunities for the local community. The distinction between the provision of sub-contracted business opportunities and employment opportunities is important. The former signifies the retention of MOTA related profits in the local community, while the latter frequently signifies the direction of profits to a party not located in the local community.

\subsection{Other issues}

Over the past 25 to 30 years, the legislation pertaining to subdivision and operation of multi-titled complexes has matured in many Australian States and Territories providing greater protection for investors and more certainty in regard to administrative procedures, including dispute resolution mechanisms [13]. Also, a better knowledge has evolved concerning MOTA unit ownership, ranging from asset surveying to financial and operational management. 
Finally, information technology advancements appear to be supporting MOTA developments. The growth of the internet, in particular, has greatly facilitated advertising and room booking management for small tourism accommodation operators. An investigation of estate agents and MOTA operator websites reveals that updates on accommodation availability and bookings can now be displayed or processed via the Internet. Improved Internet search engines are also providing greater access to tourists who, in the past, had to rely on wholesaler advertising. Further, the advent of cheaper desktop computer based booking and financial management systems are enabling many more small tourism accommodation providers to operate relatively sophisticated room management systems. These developments can be expected to have been particularly beneficial for smaller or more low-key MOTA complexes.

\section{Destination sustainability and the MOTA construct}

The key challenges for the sustainable operation of a destination entail (a) provision of a variety of nationally, and increasingly internationally, competitive and up-to-date tourist facilities (notably accommodation), (b) optimisation of energy and water usage, and (c) preservation of natural and cultural assets. With respect to MOTA developments, these criteria point to a number of challenges at very different levels of abstraction, ranging from operational management of individual buildings [10] to town and environmental management for whole destinations and, legal arrangements in dispute resolution procedures [13]. The following discussion will draw on previous work and updates of observations and critical analyses of some of the developments on Australia's Gold Coast which is widely-recognised as a premier seaside destination $[9,14]$.

\subsection{Competitive accommodation infrastructure}

A large number of MOTA complexes have been constructed during the recent property boom on the Gold Coast between 1999 and 2005. These include two major multi-tower projects and one 80 storey landmark iconic tower with an observation platform 230 metres above sea level in Surfers Paradise, the area's central tourist hub. This development activity has pushed the density of bed spaces per ground area to levels previously only found with traditional hotel towers, albeit with lower heights (as conventional hotel rooms do not have self catering areas, relative to a self-catering unit, they have a greater density of bed space for a given floor area). Prior to this boom, the average ground area per bed space was $27 \mathrm{~m}^{2}$ for MOTA complexes [9] and $11 \mathrm{~m}^{2}$ for major hotels in or near the area's tourism hubs. The new MOTA complexes in the heart of Surfers Paradise achieve between 10 and $6 \mathrm{~m}^{2}$ per bed space. No new traditional hotels on a single title have been constructed in the recent past.

These apparent trends support what has been noted by Warnken et al. [9], i.e., complexes held by a multitude of owners protected by property law rather than corporate law principles are very difficult to replace. If they are replaced, development companies are only prepared to engage if the new structure(s) allow 
for much higher densities than the previous development. The results of these developments in terms of increased traffic congestion and higher visitor densities in central tourist areas and natural asset areas (the beaches) are yet to be seen.

\subsection{Optimisation of energy and water usage}

Warnken and Bradley [15] note that waste and wastewater production of most tourist accommodation premises is hard to quantify in Queensland. Nevertheless, Warnken and Bradley [15] noted that MOTA style developments appear to be more energy and water efficient than most hotels, and even some ecoresorts. With respect to electricity consumption, MOTA developments make extensive use of ceiling fans instead of air conditioning units for room cooling. Where air conditioning is used in MOTA units, each unit tends to be isolated enabling air conditioners to be shut off rather than just turned down. Further, relative to similarly sized hotels, MOTA complexes have smaller and less recreation facilities, e.g., swimming pools. In line with trends to higher densities and larger structures, many of the more recently constructed MOTA buildings have larger foyers, and larger recreation facilities such as swimming pools. Air conditioning of all interior areas is also increasingly becoming standard, however most apartments are still fitted with separate air conditioning units, which can be shut down when apartments are unoccupied. Detailed per capita energy and water audits (e.g. [16]) still have to be carried out to unambiguously identify whether good energy and water use performances have been retained.

In terms of raw materials and resource use during construction, MOTA complexes are likely to perform less favourably than hotels and motels: the need for having to provide a full kitchen, laundry and living room for each accommodation unit simply equates to more floor space, greater wall area and more furnishings. Recently developed MOTA complexes on the Gold Coast also tend to offer a bathroom for each bedroom. This, in turn, will result in more raw materials and resources (water, energy) to be used per bed space.

\subsection{Preservation of natural and cultural assets}

Practically all of the land near the Gold Coast's prime natural asset, its $35 \mathrm{~km}$ of sandy surf beaches, has now been developed. Apart from isolated exceptions, all recent MOTA developments have occurred on already heavily disturbed sites or as redevelopment of low density urban areas, thereby consolidating densities rather than developing new sites. One notable aspect of the upmarket MOTA sub-sector is their tendency to be associated with large-scale recreation facilities, notably golf courses and marinas. The golf course or marina serves to increase the status of the complex which has the knock-on effect of inflating the prices paid for units by investors. Both, golf courses and marinas are known to generate ongoing disturbances or impacts to natural systems (see $[17,18,19]$ ).

Many profound cultural impacts are likely to result in destinations with a high incidence of MOTA development activity. The Gold Coast was marketed for a long time as a relaxed, family-friendly beach resort destination known for a 
casual atmosphere ("beautiful one day, perfect the next"). The rapidly expanding urban nightclub/restaurant/bar/shopping infrastructure that is integrated into many MOTA complexes is now being reflected by a distinctly different theme in marketing. In recent times, a younger, more dynamic image is projected ("VeryGoldCoast - Very Exciting"), with emphasis placed on sport and recreation, shopping and theme parks rather than beach and sunbathing.

\section{Conclusion}

The impact of MOTA is considerable when we recognise that during property booms, MOTA can attract a volume of investor capital that is disproportionate to the underlying demand for tourism accommodation. This phenomenon would appear to be greater for MOTA relative to hotels, because the potential purchasers of a hotel will focus on the likelihood of being able to secure a contract with a reputable hotel operator. To secure such a contract will be challenging if a destination is beginning to suffer from a degree of accommodation over-supply. Smaller investors, however, during a real estate speculative boom period, can be expected to become more caught up in a property purchasing fever fuelled by the expectation of capital gains. The size of the market for individual units is much greater than the size of the market for whole complexes, as a result, individual unit owners are better placed to realise their capital gain when seeking to liquidate their investment. This suggests that destinations with a high proportion of MOTA complexes will be more susceptible to extended periods of accommodation over-supply. Such a scenario is likely to result in price wars between the accommodation suppliers, the implementation of strategies built around cost minimising strategies and a resulting deterioration in the standing of the destination.

This issue of a deterioration in standing of a destination is particularly concerning when we remind ourselves of the earlier observation that it is far easier for a tourism accommodation complex owned under a single title to convert into a MOTA than it is for a MOTA complex to convert to a single title. Once a destination is dominated by MOTA there is little that can be done to change the destination's profile. This highlights the significance of careful consideration of the long-term implications of high MOTA density by destination planners.

In this paper we have highlighted the growth of MOTA complexes in Australia, and most notably, the Gold Coast. It has been noted that MOTA complexes present a particular set of idiosyncratic issues to the managers that run the complexes, developers who create the complexes and also local authorities that grant permission for the construction of complexes. Despite the growth of MOTA and its somewhat idiosyncratic nature, it is a form of tourism accommodation provision that has commanded negligible attention from researchers. It is hoped that this paper might stimulate much needed further research and consideration of the MOTA phenomenon in order to rectify our deficient appreciation of this increasingly common, lumbering giant. 
Letting entities

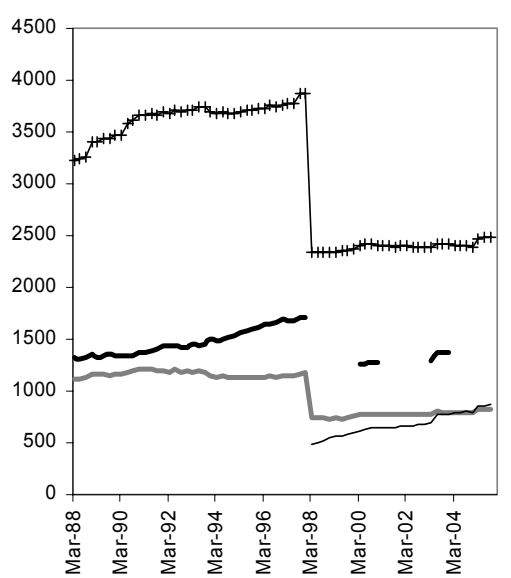

Guest nights

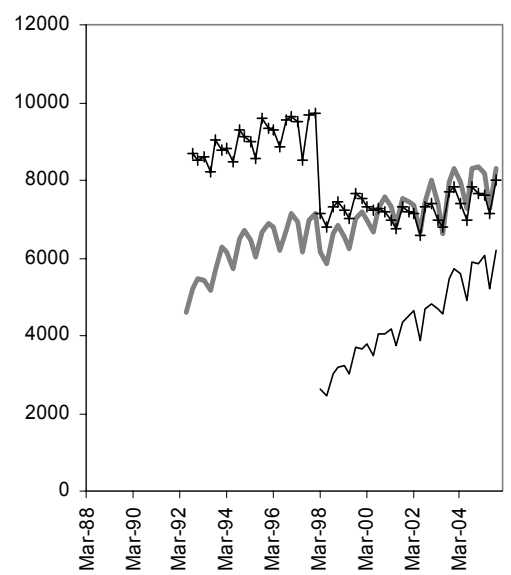

Rooms

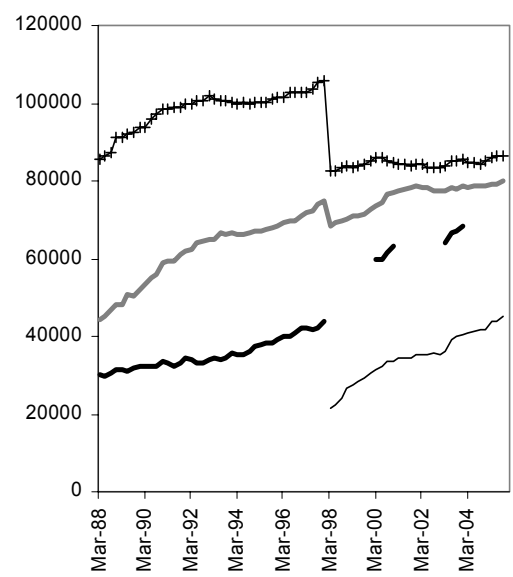

Takings '000

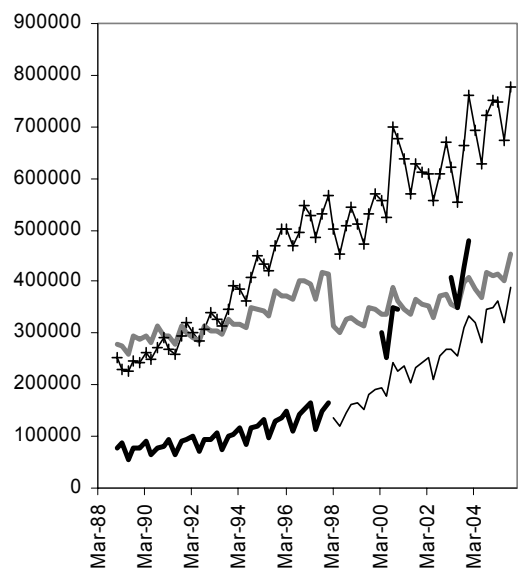

Figure 1: Quarterly tourism accommodation statistics, Australia. Compiled from Australian Bureau of Statistics (ABS) Tourist Accommodation Survey, Publication Series No. 8635.0, March 1988 - December 2005; -+-+ = hotels; $-=$ motels; $-=$ serviced apartments; $-\ldots=$ holiday homes and flats.

\section{References}

[1] Australian Bureau of Statistics (ABS), Tourist Accommodation, Australia (March Quarter), Publication No. 8635.0, ABS: Canberra. 1996. 
[2] Selwood, J. \& Tonts, M., Recreational homes in the south west of Western Australia (Chapter 10). Tourism, Mobility and Second Homes, eds. C.M. Hall \& D.K. Müller, Channel View: Clevedon and Toronto, pp. 149-161, 2004.

[3] Frost, W., A hidden giant: Second homes and coastal tourism in southeastern Australia (Chapter 11). Tourism, Mobility and Second Homes, eds. C.M. Hall \& D.K. Müller, Channel View: Clevedon and Toronto, pp. 162-173, 2004.

[4] Burnley, I. \& Murphy, P., Sea Change: movement from metropolitan to Arcadian Australia, University of New South Wales Press Ltd.: Sydney NSW, 2004.

[5] Mullins, P., Tourism urbanization. International Journal of Urban and Regional Research, 15, pp. 326-342, 1991.

[6] Smith, R.A., Coastal urbanization: Tourism development in the Asia Pacific, Built Environment, 18, pp. 27-40, 1992.

[7] Stroud, H. B., The Promise of Paradise - Recreational and Retirement Communities in the United States since 1950, Johns Hopkins University Press: Baltimore, 1995.

[8] Hajdu, J., The Gold Coast, Australia: Spatial model of its development and impact of the cycle of foreign investment in property during the late 1980's, Erdkunde, 47, pp. 40-51, 1993.

[9] Warnken, J., Russell, R. \& Faulkner, B., Condominium Developments in Maturing Destinations: Potentials and Problems for Long-Term Sustainability, Tourism Management, 24, pp.155-168, 2003.

[10] Guilding, C., Ardill, A., Fredline, E. \&Warnken, J., An agency theory perspective on the owner / manager relationship in tourism-based condominiums, Tourism Management, 26, pp. 409-420, 2005.

[11] Tourism Taskforce (TTF), Resorting to profitability, making tourist resorts work in Australia. TTF: Sydney, 2003.

[12] Warnken, J. \& Buckley, R.C., Scientific Quality of Tourism EIA. Journal of Applied Ecology, 35, pp.1-8, 1998.

[13] Everton-Moore, K., Ardill, A., Guilding, C. \& Warnken, J., The Law of Strata Title in Australia: A Jurisdictional Stocktake. Australian Property Law Journal, forthcoming.

[14] Warnken, J, Bradley M. \& Guilding, C., Eco-resorts vs. mainstream accommodation providers: An investigation of the viability of benchmarking environmental performance. Tourism Management, 26, pp. 367-379, 2005.

[15] Warnken, J. \& Bradley M., Energy Auditing and Estimating Greenhouse Gas Emissions for Australia's Tourist Accommodation Sector, Cooperative Research Centre for Sustainable Tourism (CRC research report series): Gold Coast, 2002.

[16] Warnken, J., Bradley, M. \& Guilding, C., Exploring methods and practicalities of conducting sector-energy consumption accounting in the 
tourist accommodation industry. Ecological Economics, 48, pp. 125-141, 2004.

[17] Warnken, J., Zakus, D. H. \& Thompson, D., Golf course development in a major tourist destination: implications for planning and management. Environmental Management, 27, pp. 681-696 2001.

[18] Teasdale, P., Dunn, R., Warnken J. \& Schleich, R., Evaluation of the diffusive gradient in a thin film technique for monitoring trace metal levels in estuarine waters. Environmental Science \& Technology, 37, pp. 2794-2800, 2003.

[19] Warnken, J., Dunn, R. \& Teasdale P., Investigation of recreational boats as a source of copper at anchorage sites using time-integrated diffusive gradients in thin film and sediment measurements. Marine Pollution Bulletin, 29, 833-843, 2004. 